\title{
Is It Important to Perform Physical Activity During Coronavirus Pandemic (COVID-19)? Driving Action for a Correct Exercise Plan
}

\author{
Valentina Natalucci ${ }^{1 *}$, Vittoria Carnevale Pellino ${ }^{2,3}$, Elena Barbieri ${ }^{1}$ and Matteo Vandoni ${ }^{2}$ \\ ${ }^{1}$ Division of Exercise and Health Sciences, Department of Biomolecular Science, University of Urbino Carlo Bo, Urbino, Italy, \\ ${ }^{2}$ Laboratory of Adapted Motor Activity (LAMA), Department of Public Health, Experimental and Forensic Medicine, University \\ of Pavia, Pavia, Italy, ${ }^{3}$ Department of Industrial Engineering, University of Tor Vergata, Rome, Italy
}

Keywords: exercise, physical activity guidelines, health education, COVID-19, global emergency

OPEN ACCESS

Edited by:

Allen C. Meadors,

Independent Researcher,

Seven Lakes, NC, United States

Reviewed by:

Jeff Bolles,

University of North Carolina at

Pembroke, United States

Irene Pittman Aiken,

University of North Carolina at

Pembroke, United States

Warren G. McDonald

Methodist University, United States

*Correspondence:

Valentina Natalucci

valentina.natalucci@uniurb.it

Specialty section:

This article was submitted to

Public Health Education and

Promotion,

a section of the journal

Frontiers in Public Health

Received: 02 September 2020 Accepted: 30 September 2020

Published: 02 November 2020

Citation:

Natalucci V, Carnevale Pellino V, Barbieri $E$ and Vandoni $M$ (2020) Is it Important to Perform Physical Activity

During Coronavirus Pandemic

(COVID-19)? Driving Action for a

Correct Exercise Plan.

Front. Public Health 8:602020.

doi: 10.3389/fpubh.2020.602020
Coronavirus disease (COVID-19) continues to outbreak all over the world causing a public health concern (1) and on March 11th, the pandemic was declared a public health emergency of international proportions by World Health Organization (WHO). To limit viral transmission, most governments introduced national quarantine reducing movements and social interaction with the imperative "stay at home." Lockdown is considered the extreme option to protect health and in particularly most vulnerable people (those aged $\geq 65$ years, and those with pathologies such as chronic heart, lung kidney and liver diseases, diabetes, and obesity), but it caused considerable disruption to the routine of the general population $(2,3)$. The closure of gyms, stadiums, pools, dance and fitness studios, physiotherapy centers, parks, playgrounds reduced the possibility to practice Physical Activity (PA) in outdoor setting and, in general, the exercise options $(4,5)$. Although PA and exercise management in autonomy is challenging, some authors suggest that exercise and regular PA are useful to help ease anxiety and to improve mental health and general well-being $(6,7)$. Moreover, Nieman and Wentz (8) showed the beneficial role of PA in disease prevention, as an adjuvant treatment in chronic diseases with a protective effect on the immune system, whose optimal status is crucial to respond adequately to the threat of COVID-19 (8). In this Opinion article, we analyze possible adaptations of the exercise guidelines to the current pandemic emergency, proposing an Exercise Schedule to prevent or mitigate the physical inactivity (9-11).

\section{GUIDELINES FOR PHYSICAL ACTIVITY FOR HEALTH PROMOTION}

During the initial phase of COVID-19 Pandemic (12), to ensure an optimal health status and maintain well-being and fitness, guidelines established the minimal amount of PA to practice. The WHO established guidelines on the minimal amount of PA to maintain well-being and fitness. For adults, it is recommended at least 150 min of moderate-intensity PA or 75 min of vigorous-intensity $\mathrm{PA}$, including muscle-strengthening activities twice weekly $(5,8-11)$.

\section{COVID-19 EMERGENCY: THE WAYS TO BE PHYSICALLY ACTIVE}

PA recommendations were implemented to promote an active lifestyle and improve global health. In particular, Chen et al. (13) recommended regular PA to maintain healthy physical and immune system functions in an unsafe environment and suggested various reliable, simple, and easily implementable exercises. As well as, Ricci et al. (14) proposed specific recommendations and tips for Home-Based PA management. However, COVID-19 pandemic highlighted the importance of 
TABLE 1 | Exercise schedule.

\begin{tabular}{|c|c|c|c|c|c|c|c|c|c|}
\hline \multirow{3}{*}{$\begin{array}{l}\text { PA } \\
\text { self-report } \\
\text { IPAQ zone }\end{array}$} & \multicolumn{2}{|c|}{$\begin{array}{l}\text { Perceived exertion rating } \\
\text { (6-20 RPE scale) }\end{array}$} & \multirow{3}{*}{$\frac{\text { Intensity }}{\text { Level zone }}$} & \multirow{3}{*}{$\begin{array}{c}\begin{array}{c}\text { Absolute } \\
\text { intensity }\end{array} \\
\text { METs }\end{array}$} & \multicolumn{5}{|c|}{ Example of home-and-outdoor exercise (Healthy adults $\geq 18$ years) } \\
\hline & \multirow[t]{2}{*}{ RPE } & \multirow{2}{*}{$\begin{array}{l}\text { Level of } \\
\text { exertion }\end{array}$} & & & \multirow[t]{2}{*}{ Cardiorespiratory endurance exercise } & \multicolumn{4}{|c|}{ Resistance (Strength) Exercise } \\
\hline & & & & & & Body zone & Exercise & Exercise per level of intensity & $\begin{array}{l}\text { Assisted } \\
\text { equipment or } \\
\text { resistance applied }\end{array}$ \\
\hline \multirow[t]{3}{*}{$\begin{array}{l}\text { Inactive (I) } \\
(<600 \text { MET-Min } \\
\text { week-1) }\end{array}$} & $<9$ & Very light & Very light & $<3.0$ & $\begin{array}{l}\text { Walking, } 1.7 \mathrm{mph}(2.7 \mathrm{~km} / \mathrm{h}) \text {, level ground ( } 2.3 \\
\text { METs); Walking, } 2.5 \mathrm{mph}(4 \mathrm{~km} / \mathrm{h})(2.9 \mathrm{METs}) \\
\text { Bicycling, stationary, } 50 \text { watts ( } 3.0 \mathrm{METs}) ; \\
\text { Calisthenics, home exercise, light or moderate }\end{array}$ & Upper body & Push-ups & $\begin{array}{l}\text { LI: Wall push-ups } \\
\text { LMA: Push-ups on knees } \\
\text { LA: Basic Push-ups (or advanced) }\end{array}$ & Mat \\
\hline & 9-11 & $\begin{array}{l}\text { Very light-fairly } \\
\text { light }\end{array}$ & Light & $3.1-4.0$ & effort (3.5 METs) & & Triceps extension & $\begin{array}{l}\text { LI: Low } \\
\text { LMA: Medium } \\
\text { LA: High }\end{array}$ & $\begin{array}{l}\text { Elastic band } \\
\text { (Therabands) }\end{array}$ \\
\hline & & & & & & & Shoulder press & $\begin{array}{l}\text { LI: Low } \\
\text { LMA: Medium } \\
\text { LA: High }\end{array}$ & $\begin{array}{l}\text { Elastic band } \\
\text { (Therabands) }\end{array}$ \\
\hline \multirow[t]{5}{*}{$\begin{array}{l}\text { Moderate Active } \\
\text { (MA) } \\
(\geq 600 \text { as }<3000 \\
\text { MET-Min week-1) }\end{array}$} & $12-14$ & $\begin{array}{l}\text { Fairly light to } \\
\text { somewhat hard }\end{array}$ & Moderate & $3.0-5.9$ & $\begin{array}{l}\text { Bicycling, stationary, } 100 \text { watts ( } 5.5 \mathrm{METs}) \text {; } \\
\text { Walking } 3.0 \mathrm{mph}(4.8 \mathrm{~km} / \mathrm{h})(3.3 \mathrm{METs}) \text {; } \\
\text { Calisthenics, home exercise, light or moderate } \\
\text { effort ( } 3.5 \mathrm{METs}) \text {; Walking } 3.4 \mathrm{mph}(5.5 \mathrm{~km} / \mathrm{h})(3.6\end{array}$ & $\begin{array}{l}\text { Lower body } \\
6\end{array}$ & Squats & $\begin{array}{l}\text { LI: Bodyweight squat } \\
\text { LMA: Squat jump } \\
\text { LA: Single leg squat }\end{array}$ & Mat \\
\hline & & & & & METs) & & Walking lunges & $\begin{array}{l}\text { LI: Slider revers lunge } \\
\text { LMA: Pendulum lunge } \\
\text { LA: Skater squat }\end{array}$ & Mat \\
\hline & & & & & & & $\begin{array}{l}\text { Side-lying hip } \\
\text { abduction }\end{array}$ & $\begin{array}{l}\text { LI: Low } \\
\text { LMA: Medium } \\
\text { LA: High }\end{array}$ & $\begin{array}{l}\text { Elastic band } \\
\text { (Therabands) }\end{array}$ \\
\hline & & & & & & & Calf-raise & $\begin{array}{l}\text { LI: Seated calf raise } \\
\text { LMA: Single-leg standing calf raise with } \\
\text { assistance }\end{array}$ & Mat \\
\hline & & & & & & & Bridge & $\begin{array}{l}\text { LA: Sigle-leg standing calf raise } \\
\text { Li: Basic bridge (two legs) } \\
\text { LMA: Single leg bridge } \\
\text { LA: Swiss ball bridge }\end{array}$ & $\begin{array}{l}\text { Elastic band } \\
\text { (Therabands) }\end{array}$ \\
\hline \multirow[t]{3}{*}{$\begin{array}{l}\text { Active (A) } \\
(\geq 3000 \text { MET-Min } \\
\text { week-1) }\end{array}$} & $15-17$ & $\begin{array}{l}\text { Somewhat hard } \\
\text { to very hard }\end{array}$ & Vigorous & $6.0-8.7$ & $\begin{array}{l}\text { Jogging, general ( } 7.0 \mathrm{METs}) \text {; Calisthenics (e.g., } \\
\text { push-ups, sit-ups, pullups, jumping jacks), } \\
\text { heavy, vigorous effort ( } 8.0 \mathrm{METs}) \text {; Running }\end{array}$ & $\begin{array}{l}\text { Abdominal } \\
\text { and core }\end{array}$ & Crunches & $\begin{array}{l}\text { LI: Basic crunches } \\
\text { LMA: Crunches reverse } \\
\text { LA: Bicycle crunches }\end{array}$ & Mat \\
\hline & & & & & & & Plank & $\begin{array}{l}\text { LI: Plank with both Knees Bent } \\
\text { LMA: Plank full } \\
\text { LA: Plank with legs lifts (or advanced) }\end{array}$ & Mat \\
\hline & & & & & & & Bird dog & $\begin{array}{l}\text { LI: Twisted bird dog } \\
\text { LMA: Basic bird dog } \\
\text { LA: Bird dog pushup }\end{array}$ & Mat \\
\hline
\end{tabular}

MET-min, metabolic equivalents (MET) of energy expenditure for a physical activity performed for a given number of minutes (min), calculated as MET × mins; LI, Level Inactive; LMA, Level Moderate Active; LA, Level Active. 
understanding common barriers to PA practice and contrast sedentary creating strategies both for exercise specialists and general population. PA in healthy individuals can be selfdirected or supervised by exercise professionals (such as trainers, specialists in sport sciences, kinesiologists) that are conscious of exercise prescription FITT-VP principle [i.e., frequency $(\mathrm{F})$, intensity $(\mathrm{I})$, time $(\mathrm{T})$, type $(\mathrm{T})$, volume $(\mathrm{V})$, and progression (P) over time]. In fact, it is crucial to differentiate the concept of "exercise" compared to "PA": exercise is a subset of planned, structured and repeated PA with the aim of improve or maintain physical fitness. People, during the COVID-19 lockdown, tried to contrast sedentary behavior with various strategies without the use of specialized technology and equipment (i.e., brisk walking, stair climbing, yard or house-work and playing active). Nevertheless, the use of exercise technologies evolved to facilitate and support people in PA practice involving people, coaches and clinicians with adequate support and education. In fact, the virtual environment is attractive and could be a safe and reliable solution to contrast sedentary. There are many platforms or applications free of charge that help people to maintain healthy habits and an active lifestyle.

\section{A POTENTIAL NEW WAY TO PROMOTE AN ACTIVE LIFESTYLE}

The role of exercise specialists in the community and health care system is increasingly important, as well as a way to promote a strategy for driving healthy community to safely and effectively prevent most chronic illness through an active lifestyle. For this reason, we have developed an Exercise Schedule focused on practical applications and recommendations to help people to provide people with guidelines to help them exercise by themselves. Exercise specialists, following FITT-VP supported principles will be able to adapt the Exercise Schedule to peculiar capacities of people and different training environments. The home-based exercise programs can be delivered by exercise specialists exploiting the using telehealth (or telemedicine), i.e., the remote delivery of health care as well as a range of other services such as wellness promotion through technology (15). Moreover, the home-based exercise programs are reasonable, usually well-accepted thanks to the possibility to involve entire families during leisure time. The Exercise Schedule presented in Table 1. is addressed to healthy people without any diagnosis of illness and, considering the actual exercise prescription guidelines (16), suggests a mixed (aerobic and resistance) training program. Preliminary to engage any fitness program, sedentary people and those with health issues or concerns may need to consult with medical staff before starting a new exercise routine. However, the American College of Sports Medicine recommendations simplify the pre-screening process by eliminating the need for medical clearance and/or exercise testing in many individuals, especially when low-to moderate intensity exercise is contemplated.

To better adapt our program to individual training level, we suggest to self-evaluate PA level through the International Physical Activity Questionnaire (IPAQ) (17) prior to approaching the training and to manage the intensity with Rate Perceived Exertion (RPE) through the Borg RPE Scale (18). The Borg Scale takes into account fitness level: it runs from 6 to 20 and multiplying the Borg score by 10 gives an approximate heart rate for a particular level of activity. Aerobic training should be performed 3-5 times per week while resistance training 23 times per week. In general, people could improve duration, intensity and difficulty of training when they feel confident with their routine. Our program provides aerobic activities controlled for intensity by RPE for inactive (6-11 RPE), moderate active (12-14 RPE) and active people (15-17). We excluded to train people with higher levels of RPE for the risk to reach anaerobic intensities. Moreover, exercises were selected following Metabolic Equivalent Tasks (METs) intensities (19) and take into account initial evaluation of self-reported PA level. The duration of each training session should last from 20 (Inactive people) till to 60 (Active people) min. Resistance training was designed specifying body zones and with different modalities of execution. To help people and facilitate exercise execution, we suggested elastic resistance training (ERT) for some exercises. Its benefits include improved functional capacity, increased strength and endurance and represent safe equipment during homeconfinement (20). Exercises should be repeated from 8 to 12 times per session. Finally, a warm-up and a cool-down phase for every training session should include a 5-10 min routine of neuromuscular, mobility and flexibility for the main muscular groups (21).

\section{TRANSLATION TO HEALTH EDUCATION PRACTICE}

This document, through an Exercise Schedule, provides information and practical applications to drive people to achieve PA guidelines recommendations. Many people need to increase their activity level and adopt a more active lifestyle. Technology can play a role in providing them the information and support the need to do so. Improving people's health will ameliorate some health issues and reduce health care costs. This is particularly needed given the impact and costs of the current COVID-19 Pandemic on the health care system. The challenge for exercise specialists is to provide safe and effective exercise programs that people will adhere to in the long term. We are strongly convinced that using the present information to manage types, duration, and intensities of exercise will permit people to enrich PA experience and to achieve better health outcomes.

\section{AUTHOR CONTRIBUTIONS}

$\mathrm{VN}$ : conceptualization, wrote-original draft, review and editing, and planned and project training protocol. VC: wrote-original draft and planned and project training protocol. EB: supervision. MV: conceptualization, wrote-original draft, review and editing, and supervision. All authors contributed to the article and approved the submitted version. 


\section{REFERENCES}

1. Wu F, Zhao S, Yu B, Chen YM, Wang W, Song ZG, et al. A new coronavirus associated with human respiratory disease in China. Nature. (2020) 579:265-9. doi: 10.1038/s41586-020-2008-3

2. Assaloni R, Carnevale Pellino V, Puci MV, Ferraro OE, Lovecchio N, Girelli A, et al. Coronavirus disease (Covid-19): how does the exercise practice in active people with Type 1 DIABETES change? A preliminary survey. Diabetes Res Clin Pract. (2020) 166:108297. doi: 10.1016/j.diabres.2020.108297

3. Calcaterra V, Vandoni M, Pellino VC, Cena H. Special attention to diet and physical activity in children and adolescents with obesity during the coronavirus disease-2019 pandemic. Front Pediatr. (2020) 8:407. doi: 10.3389/fped.2020.00407

4. Colley RC, Bushnik T, Langlois K. Exercise and screen time during the COVID-19 pandemic. Health Rep. (2020) 31:1-11. doi: 10.25318/82-003-x202000600001-eng

5. Hall G, Laddu DR, Phillips SA, Lavie CJ, Arena R. A tale of two pandemics: how will COVID-19 and global trends in physical inactivity and sedentary behavior affect one another? Prog Cardiovasc Dis. (2020). doi: 10.1016/j.pcad.2020.04.005. [Epub ahead of print].

6. Anderson E, Shivakumar G. Effects of exercise and physical activity on anxiety. Front Psychiatry. (2013) 4:27. doi: 10.3389/fpsyt.2013.00027

7. Sharma A, Madaan V, Petty FD. Exercise for mental health. Prim Care Companion J Clin Psychiatry. (2006) 8:106. doi: 10.4088/PCC.v08n0208a

8. Nieman DC, Wentz LM. The compelling link between physical activity and the body's defense system. J Sport Heal Sci. (2019) 8:201-17. doi: 10.1016/j.jshs.2018.09.009

9. Pedersen BK, Saltin B. Exercise as medicine-evidence for prescribing exercise as therapy in 26 different chronic diseases. Scand J Med Sci Sports. (2015) 25:1-72. doi: $10.1111 /$ sms. 12581

10. Atkin AJ, Gorely T, Clemes SA, Yates T, Edwardson C, Brage S, et al. Methods of measurement in epidemiology: sedentary behaviour. Int J Epidemiol. (2012) 41:1460-71. doi: 10.1093/ije/dys118

11. De Rezende LFM, Lopes MR, Rey-Loṕez JP, Matsudo VKR, Luiz ODC. Sedentary behavior and health outcomes: an overview of systematic reviews. PLoS ONE. (2014) 9:e105620. doi: 10.1371/journal.pone.0105620

12. Rothan HA, Byrareddy SN. The epidemiology and pathogenesis of coronavirus disease (COVID-19) outbreak. J Autoimmun. (2020) 109:102433. doi: 10.1016/j.jaut.2020.102433

13. Chen P, Mao L, Nassis GP, Harmer P, Ainsworth BE, Li F. Wuhan coronavirus (2019-nCoV): the need to maintain regular physical activity while taking precautions. J Sport Heal Sci. (2020) 9:103-4. doi: 10.1016/j.jshs.2020. 02.001

14. Ricci F, Izzicupo P, Moscucci F, Sciomer S, Maffei S, Di Baldassarre A, et al. Recommendations for physical inactivity and sedentary behavior during the coronavirus disease (COVID-19) pandemic. Front Public Health. (2020) 8:199. doi: 10.3389/fpubh.2020.00199

15. Marcoux RM, Vogenberg FR. Telehealth: applications from a legal and regulatory perspective. $P$ T. (2016) 41:567. Available online at: https://www. ncbi.nlm.nih.gov/pmc/articles/PMC5010268/ (accessed August 28, 2020).

16. American College of Sports Medicine. ACSM Guidelines for Exercise Testing and Preescripción. Philadelphia, PA: Wolters Kluwer Health (2018).

17. Hallal PC, Victora CG. Reliability and validity of the international physical activity questionnaire (IPAQ) [2]. Med Sci Sports Exerc. (2004) 36:556. doi: 10.1249/01.MSS.0000117161.66394.07

18. Borg GA. Psychophysical bases of perceived exertion. Med Sci Sports Exerc. (1982) 14:377-81. doi: 10.1249/00005768-19820500000012

19. Ainsworth BE, Haskell WL, Herrmann SD, Meckes N, Bassett DR, Tudor-Locke C, et al. 2011 compendium of physical activities. Med Sci Sport Exerc. (2011) 43:1575-81. doi: 10.1249/MSS.0b013e31821 ece12

20. De Oliveira PA, Blasczyk JC, Junior GS, Lagoa KF, Soares M, De Oliveira RJ, et al. Effects of elastic resistance exercise on muscle strength and functional performance in healthy adults: a systematic review and meta-analysis. J Phys Act Health. (2017) 14:317-27. doi: 10.1123/jpah.2016-0415

21. Karvonen J. Importance of warm-up and cool down on exercise performance. In: Karvonen J, Lemon PWR, Iliev I, editors. Medicine in Sports Training and Coaching. Basel: Karger Publishers (1992). p. 189-214. doi: $10.1159 / 000421152$

Conflict of Interest: The authors declare that the research was conducted in the absence of any commercial or financial relationships that could be construed as a potential conflict of interest.

Copyright (c) 2020 Natalucci, Carnevale Pellino, Barbieri and Vandoni. This is an open-access article distributed under the terms of the Creative Commons Attribution License (CC BY). The use, distribution or reproduction in other forums is permitted, provided the original author(s) and the copyright owner(s) are credited and that the original publication in this journal is cited, in accordance with accepted academic practice. No use, distribution or reproduction is permitted which does not comply with these terms. 